\title{
Graphene-templated synthesis of sandwich-like porous carbon nanosheets for efficient oxygen reduction reaction in both alkaline and acidic media
}

\author{
Tao Wang ${ }^{1}$, Jianyu Wang ${ }^{2}, \mathrm{Xu}$ Wang ${ }^{1}$, Jia Yang ${ }^{1}$, Jianguo $\mathrm{Liu}^{2^{*}}$ and Hangxun $\mathrm{Xu}^{1^{*}}$
}

\begin{abstract}
Developing low-cost, high-performance electrocatalysts for the oxygen reduction reaction (ORR) is crucial for implementation of fuel cells and metal-air batteries into practical applications. Graphene-based catalysts have been extensively investigated for ORR in alkaline electrolytes. However, their performance in acidic electrolytes still requires further improvement compared to the $\mathrm{Pt} / \mathrm{C}$ catalyst. Here we report a self-templating approach to prepare graphene-based sandwich-like porous carbon nanosheets for efficient ORR in both alkaline and acidic electrolytes. Graphene oxides were first used to adsorb $m$-phenylenediamine molecules which can form a nitrogen-rich polymer network after oxidative polymerization. Then iron (Fe) salt was introduced into the polymer network and transformed into ORR active $\mathrm{Fe}-\mathrm{N}-\mathrm{C}$ sites along with $\mathrm{Fe}, \mathrm{FeS}$, and $\mathrm{FeN}_{0.05}$ nanoparticles after pyrolysis, generating ORR active sandwich-like carbon nanosheets. Due to the presence of multiple ORR active sites. The as-obtained catalyst exhibited prominent ORR activity with a half-wave potential $\sim 30 \mathrm{mV}$ more positive than $\mathrm{Pt} / \mathrm{C}$ in $0.1 \mathrm{~mol} \mathrm{~L}^{-1} \mathrm{KOH}$, while the half-wave potential of the catalyst was only $\sim 40 \mathrm{mV}$ lower than that of commercial $\mathrm{Pt} / \mathrm{C}$ in 0.1 mol $\mathrm{L}^{-1} \mathrm{HClO}_{4}$. The unique planar sandwich-like structure could expose abundant active sites for ORR. Meanwhile, the graphene layer and porous structure could simultaneously enhance electrical conductivity and facilitate mass transport. The prominent electrocatalytic activity and durability in both alkaline and acidic electrolytes indicate that these carbon nanosheets hold great potential as alternatives to precious metalbased catalysts, as demonstrated in zinc-air batteries and proton exchange membrane fuel cells.
\end{abstract}

Keywords: oxygen reduction reaction, porous carbon, nanosheets, fuel cells, zinc-air batteries

\section{INTRODUCTION}

With the emerging global energy crisis and the growing environmental concerns, the development of efficient and renewable energy conversion and storage devices has become a critically important research topic. Fuel cells and metal-air batteries are two of the most promising electrochemical energy conversion devices with high energy utilization and safety [1-5]. However, the lack of efficient and low-cost electrocatalysts toward oxygen reduction reaction (ORR) occurring at the cathodes of fuel cells and metal-air batteries impedes the implementation of metal-air batteries and fuel cells in practical applications [6-10]. Although Pt-based precious metal catalysts possess the most intriguing catalytic performance in prototype devices, the high cost associated with poor durability is a severe issue preventing their further development $[11,12]$. Therefore, it is urgent to develop alternative non-precious metal catalysts (NPMCs) with high electrocatalytic activity and long-term stability to promote the commercialization of metal-air batteries and fuel cells in the near future [13-19].

Recently, NPMCs containing transition meal-nitrogencarbon ( $\mathrm{M}-\mathrm{N}-\mathrm{C}, \mathrm{M}=\mathrm{Fe}, \mathrm{Co})$ sites have attracted considerable attention due to their prominent catalytic performance in alkaline media [18-24]. In particular, Fe/Ndoped carbon electrocatalysts have been considered as a very promising family of NPMCs for ORR because of the high catalytic activity, easy access, and cheap iron resources [24-32]. However, the ORR activity of $\mathrm{Fe}-\mathrm{N}-\mathrm{C}$ catalysts still remains deficient compared to that of $\mathrm{Pt}$ based catalysts in acidic media, owing to the low density of active sites [33-38]. Meanwhile, the specific surface

\footnotetext{
${ }^{1}$ CAS Key Laboratory of Soft Matter Chemistry, Department of Polymer Science and Engineering, University of Science and Technology of China, Hefei 230026, China

${ }^{2}$ National Laboratory of Solid State Microstructures, College of Engineering and Applied Sciences, Collaborative Innovation Center of Advanced Microstructures, Nanjing University, Nanjing 210093, China

"Corresponding authors (emails: hxu@ustc.edu.cn (Xu H); jianguoliu@nju.edu.cn (Liu J))
} 
area and porous structure of carbon-based NPMCs have influence on the accessibility of the active sites and ORR activity [39-43]. Consequently, rational design of porous carbon structures with abundant $\mathrm{Fe}-\mathrm{N}-\mathrm{C}$ active sites is highly desired. In this context, graphene is a very intriguing candidate for constructing two-dimensional (2D) porous NPMCs $[44,45]$. The 2D planar nature would be beneficial for exposing active sites on the surface and transporting/exchanging ORR-relevant species [46]. Moreover, the highly conductive nature of graphene could further facilitate charge transfer during ORR [47]. Nonetheless, metal species are difficult to be directly doped into pure graphene due to the lack of strong bonding between metal species and graphene. Due to strong coordination with amines of metal ions, it is a potentially viable approach that a layer of nitrogen-rich polymer with multiple coordination sites for metal species which can then be transformed into M-N-C sites after pyrolysis is coated on the surface of graphene [4850].

Herein, we report the graphene-templated synthesis of sandwich-like porous carbon nanosheets in which each graphene nanosheet is encapsulated by a porous carbon shell with multiple dopants (i.e., $\mathrm{N}, \mathrm{S}$, and $\mathrm{Fe}-\mathrm{N}$ ) and embedded nanoparticles (i.e., $\mathrm{Fe}, \mathrm{FeS}$, and $\mathrm{FeN}_{0.05}$ ). Crosslinked poly $(m$-phenylenediamine) (P $m$ PDA) layer was initially formed on graphene oxides (GO) as nitrogen sources and anchoring sites for $\mathrm{Fe}^{3+}$ ions. After adsorption and pyrolysis of $\mathrm{Fe}^{3+}$ ions, porous carbon nanosheets with a high surface area $\left(1105 \mathrm{~m}^{2} \mathrm{~g}^{-1}\right)$ can be obtained (hereafter referred to as the PmPDA-GR-Fe catalyst). $\mathrm{P} m \mathrm{PDA}$ contains more nitrogen content than polyaniline and polypyrrole, which can provide more nitrogen sources and coordination sites for $\mathrm{Fe}$ and thus could potentially enhance the electrocatalytic performance. In addition to $\mathrm{N}$-doping, $\mathrm{S}$ could also be introduced into the carbon nanosheets during the oxidative polymerization process by using ammonium persulfate (APS) as the oxidant. In this way, the doping step is simplified while the element utilization efficiency is improved. Moreover, the existence of nanoparticles such as $\mathrm{Fe}, \mathrm{FeS}$, and $\mathrm{FeN}_{0.05}$ could further boost the ORR activity by tuning the redox properties of surrounding carbon layers embedded with active sites [51]. Consequently, the resulting P $m$ PDA-GRFe catalyst exhibited prominent ORR activity as well as excellent long-term stability both in alkaline and acidic media, surpassing those of commercial $\mathrm{Pt} / \mathrm{C}$ catalyst (20 $\mathrm{wt} \% \mathrm{Pt}$, Johnson Matthey). To assess the potential of this ORR catalyst for practical applications, the P $m$ PDA-GRFe catalyst was further assembled as cathodes for a zinc- air battery and a proton exchange membrane fuel cell (PEMFC), respectively. Both results indicated that the P $m$ PDA-GR-Fe catalyst exhibited excellent ORR activity in real electrochemical devices, suggesting that the reported catalyst is very promising for practical applications.

\section{EXPERIMENTAL SECTION}

\section{Synthetic procedures}

In a typical synthesis, $1 \mathrm{~g} m$-phenylenediamine ( $m P D A)$ dissolved in $30 \mathrm{~mL} 1 \mathrm{~mol} \mathrm{~L}^{-1} \mathrm{HCl}$ solution was mixted with a $50 \mathrm{~mL}$ GO solution containing $45 \mathrm{mg}$ GO. Meanwhile, $4 \mathrm{~g}$ ammonium persulfate (APS) was dissolved in $50 \mathrm{~mL} 1 \mathrm{~mol} \mathrm{~L}^{-1} \mathrm{HCl}$ solution. Both solutions were cooled to $4^{\circ} \mathrm{C}$. Then, the APS solution was slowly added to the mixed $m \mathrm{PDA} / \mathrm{GO}$ solution with vigorous stirring. After reaction for $8 \mathrm{~h}$, the dark colored product was washed to be neutral with water several times. Finally, dried P $m$ PDA-GO powder was obtained after vacuum drying for $12 \mathrm{~h}$ at $80^{\circ} \mathrm{C}$. The dry powder of PmPDA-GO $(0.1 \mathrm{~g})$ was added into a $0.08 \mathrm{~mol} \mathrm{~L}^{-1} \mathrm{Fe}$ $\left(\mathrm{NO}_{3}\right)_{3}$ solution. After $\sim 24 \mathrm{~h}$, the solvent was removed using a rotary evaporator. Then, the resulting powder was heated at $900^{\circ} \mathrm{C}$ under $\mathrm{N}_{2}$ atmosphere for $2 \mathrm{~h}$. Subsequently, the pyrolyzed sample was added into $1 \mathrm{~mol} \mathrm{~L}^{-1}$ $\mathrm{HCl}$ solution at $80^{\circ} \mathrm{C}$ for $12 \mathrm{~h}$ followed by centrifugation and washing with deionized water. This step was performed to remove electrochemically inactive and unstable species. Finally, the obtained powder was pyrolyzed at the same temperature for $2 \mathrm{~h}$, leading to the final catalyst denoted as PmPDA-GR-Fe.

\section{Materials characterization}

Scanning electron microscopy (SEM) was performed on a FEI SIRION200 microscope. High-resolution transmission electron microscopy (HRTEM) was conducted on a JEM-ARM 200F Atomic Resolution Analytical Microscope operating at an accelerating voltage of $200 \mathrm{kV}$. Powder X-ray diffraction (PXRD) patterns were obtained using a Japan Rigaku DMax- $\gamma$ A rotation anode X-ray diffractometer. The $\mathrm{N}_{2}$ adsorption-desorption experiments were carried out using the Belsorp-max instrument. X-ray photoelectron spectroscopy (XPS) measurements were performed on an X-ray photoelectron spectrometer (Thermo ESCALAB 250).

\section{Electrochemical measurements}

All electrochemical measurements were performed in a 
three-electrode system using a PGSTAT302N electrochemical workstation (Metrohm Autolab) at room temperature. A $5.0 \mathrm{~mm}$ glassy carbon rotating disk electrode (PINE Research Instrumentation, USA) served as the substrate for working electrode. A platinum sheet and saturated calomel electrode served as the counter and reference electrodes, respectively. The reference electrode was calibrated with respect to reversible hydrogen electrode (RHE) before each experiment. The glassy carbon electrode was thoroughly cleaned before each test. To prepare the working electrode, $2 \mathrm{mg}$ of the catalyst was dispersed in $1 \mathrm{~mL}$ ethanol and sonicated to get a homogeneous ink, followed by adding $10 \mu \mathrm{L} 5 \%$ Nafion solution. Then, the catalyst ink was drop-casted on the glassy carbon electrode and dried at room temperature (catalyst loading: $\sim 0.2 \mathrm{mg} \mathrm{cm}^{-2}$ in alkline media, $\sim 0.4 \mathrm{mg} \mathrm{cm}^{-2}$ in acidic media).

For ORR measurements, the cyclic voltammetry (CV) experiments were performed in $\mathrm{Ar} / \mathrm{O}_{2}$ saturated $0.1 \mathrm{~mol} \mathrm{~L}^{-1} \mathrm{KOH}$ and $0.1 \mathrm{~mol} \mathrm{~L}^{-1} \mathrm{HClO}_{4}$ at room temperature with a scan rate of $10 \mathrm{mV} \mathrm{s}^{-1}$. Rotating disk electrode (RDE) tests were performed in $\mathrm{O}_{2}$ saturated 0.1 mol L ${ }^{-1} \mathrm{KOH}$ and $0.1 \mathrm{~mol} \mathrm{~L}^{-1} \mathrm{HClO}_{4}$ with a scan rate of $10 \mathrm{mV} \mathrm{s}^{-1}$. The electron transfer number during ORR was calculated by Koutecky-Levich equation. Rotating ringdisk electrode (RRDE) measurements were carried out to determine the four-electron selectivity according to the previous report [25].

\section{Zinc-air battery and fuel cell tests}

Zinc-air batteries were assembled in home-made cells. For example, a zinc-air battery was assembled by pairing the as-synthesized catalyst ink loaded on a porous carbon paper electrode $\left(0.5 \mathrm{mg} \mathrm{cm}^{-2}\right)$ with a $\mathrm{Zn}$ foil in $6 \mathrm{~mol} \mathrm{~L}^{-1}$ $\mathrm{KOH}$. PEMFC cathode catalyst was PmPDA-GR-Fe with a loading mass of $4 \mathrm{mg} \mathrm{cm}^{-2}$ or $60 \mathrm{wt} \% \mathrm{Pt} / \mathrm{C}$ from Johnson Matthey with a loading mass of $0.8 \mathrm{mg} \mathrm{cm}^{-2}$. To enhance protonic conductivity, $60 \mathrm{wt} \%$ of Nafion content in cathode catalyst layer was used. The anode catalyst was $60 \mathrm{wt} \% \mathrm{Pt} / \mathrm{C}$ with a loading mass of $0.8 \mathrm{mg} \mathrm{cm}^{-2}$, and the Nafion content in anodic catalyst layer was $30 \mathrm{wt} \%$. The catalyst layer in the anode and the cathode was brushed on the gas diffusion layer (Sunrise Power Inc. China) based on Toray 060 carbon paper. Then, the membrane electrode assembly (MEA) was prepared by hot-pressing the electrodes and Nafion 211 membrane with an active area of $1.0 \mathrm{~cm}^{2}$. Fuel cell polarization curve was tested at $80^{\circ} \mathrm{C}$ on a fuel cell test system (Model $850 \mathrm{e}$, Scribner Associates Inc.). $\mathrm{H}_{2}$ and $\mathrm{O}_{2}$ flow rates were $300 \mathrm{~mL} \mathrm{~min}^{-1}$ at $100 \% \mathrm{RH}$, and no back pressure was applied (i.e., the

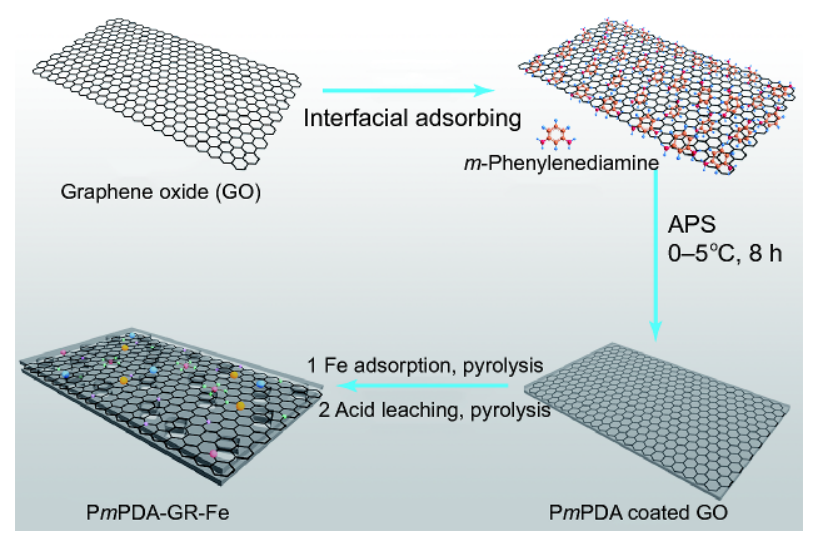

Scheme 1 Schematic illustration for the preparation of sandwich-like heteroatom-doped carbon nanosheets. Graphene oxides were first used as the template to adsorb $m$-PDA followed by an in situ polymerization process. Subsequently, after adsorbing $\mathrm{Fe}^{3+}$ ions, the polymer coated graphene oxides were subjected to pyrolysis and acid leaching, leading to the final PmPDA-GR-Fe catalyst.

$\mathrm{O}_{2}$ and $\mathrm{H}_{2}$ partial pressure was about 0.53 bar since the saturation water vapor pressure at $80^{\circ} \mathrm{C}$ is ca. 0.47 bar).

\section{RESULTS AND DISSCUSIONS}

The PmPDA-GR-Fe catalyst was prepared following the procedures schematically shown in Scheme 1. Briefly, $m$ PDA monomers were first adsorbed onto GO surface due to $\pi-\pi$ interactions, hydrogen bonding and electrostatic interactions (Fig. S1). Subsequently, P $m$ PDA layer was formed on GO surface by in situ polymerization using APS as the oxidant to yield the PmPDA-GO hybrid. As shown in Fig. S2, the thickness of the sheet-like structure is $\sim 4 \mathrm{~nm}$, indicating the PmPDA layer successfully coated on GO. PmPDA-GO was then mixed with proper amount of ferric nitrate solution for $24 \mathrm{~h}$ to introduce Fe species into the hybrid. After drying, the mixed sample was subjected to pyrolysis at $900^{\circ} \mathrm{C}$ in $\mathrm{N}_{2}$ atmosphere for $2 \mathrm{~h}$. The pyrolyzed product was leached in hot $\mathrm{HCl}$ solution to remove unstable and electrochemically inactive species. Finally, the leached sample was annealed under the same temperature for $2 \mathrm{~h}$ to afford the PmPDA-GR-Fe electrocatalyst with a sandwich-like structure.

The detailed microstructure was further examined by using SEM and transmission electron microscope (TEM). As shown in Fig. 1a and d, GO could successfully act as the template to form sheet-like structure by in situ polymerization $m \mathrm{PDA}$ monomers into $\mathrm{P} m \mathrm{PDA}$ on the surface of GO. Meanwhile, the 2D sheet-like structure still retained after pyrolysis to yield P $m$ PDA-GR (Fig. 1a, d). After introducing $\mathrm{Fe}$ into the polymer network, many visible pores and nanoparticles were formed after carbo- 


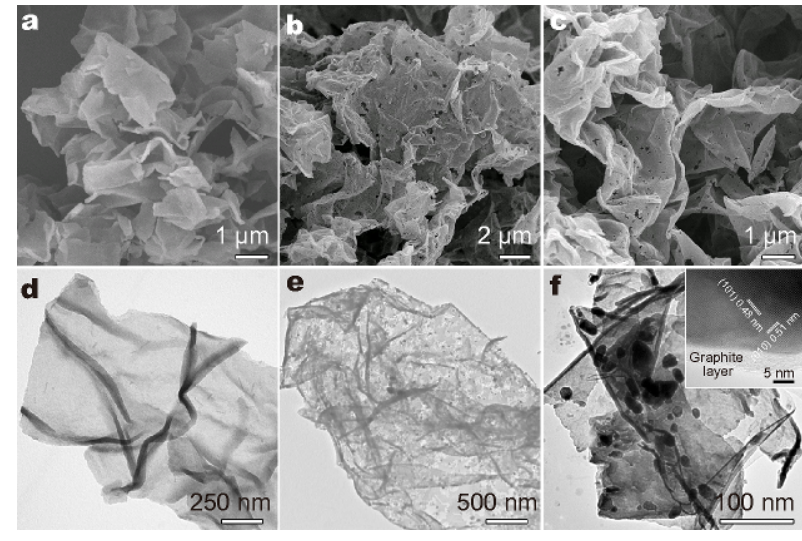

Figure 1 (a, d) SEM and TEM images of PmPDA-GR. (b, e) SEM and TEM images of PmPDA-GR-Fe before acid leaching. (c, f) SEM and TEM images of the final PmPDA-GR-Fe catalyst. The FeS nanoparticles encapsulated in graphitic carbons were identified with the index crystal plane displayed in the inset in (f).

nization (Fig. 1b, e). However, after acid leaching process, almost all of the visible nanoparticles that exposed to the outside of the nanosheets disappeared in PmPDA-GR-Fe and some large pores are clearly seen (Fig. 1c), suggesting that introducing Fe species is beneficial for the formation of porous structures. Although nanoparticles could not be observed in SEM image as shown in Fig. 1c, TEM image (Fig. 1f) clearly indicates the presence of nanoparticles with sizes of tens of nanometers in the final sandwich-like structure. The inset in Fig. If shows a typical nanoparticle with the spacing of the crystalline lattices in two directions, 0.48 and $0.51 \mathrm{~nm}$, respectively, corresponding to (101) and (010) planes of the FeS phase [52]. Moreover, the crystalline carbon layer can be easily identified as the (002) plane of graphitic carbon with an interlayer spacing of $0.34 \mathrm{~nm}$. The encapsulated FeS nanoparticles could activate the surrounding graphitic layers, making the outer carbon layers highly active toward ORR $[53,54]$.

Elemental mapping results (Fig. 2) demonstrate that both $\mathrm{C}$ and $\mathrm{N}$ are uniformly distributed in the carbon nanosheets. The strong Fe element signals exist in the areas of nanoparticles, indicating the formation of $\mathrm{Fe}$ based nanoparticles during pyrolysis. Meanwhile, $\mathrm{S}$ element was observed from the mapping results which also distributed over the carbon nanosheets. By comparing the $\mathrm{Fe}$ and $\mathrm{S}$ mapping images, we could find that there are other Fe-based nanoparticles other than FeS. As shown in powder X-ray diffraction (PXRD) patterns (Fig. 3a), the diffraction peaks can be assigned to the FeS, Fe, and $\mathrm{FeN}_{0.05}$, which are consistent with the elemental mapping results. Raman spectra (Fig. S3) reveal the characteristic G and $\mathrm{D}$ bands of carbon, corresponding to the graphitic

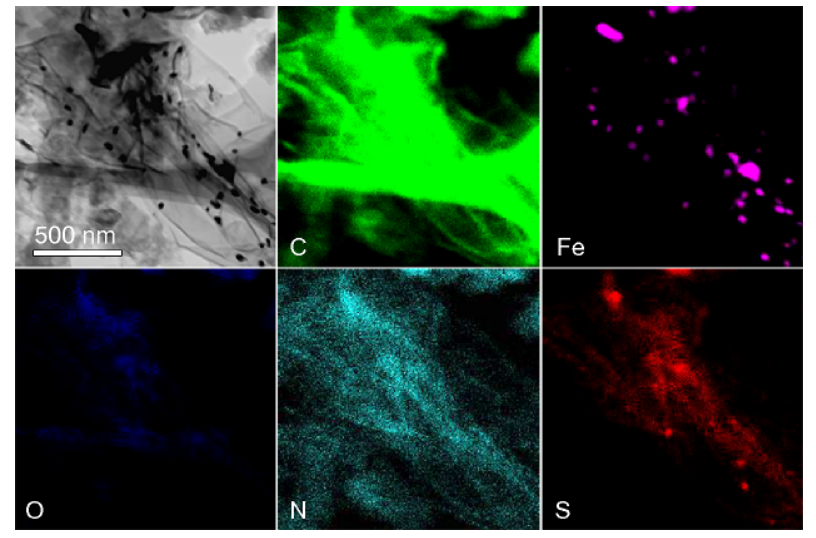

Figure 2 HAADF-STEM image of the PmPDA-GR-Fe catalyst and the corresponding EDX elemental mapping images for $\mathrm{C}, \mathrm{Fe}, \mathrm{O}, \mathrm{N}$, and $\mathrm{S}$ elements.

and disordered or defect carbons, respectively. Elemental analysis (EA) and inductively coupled plasma mass spectrometry (ICP-MS) indicated that the C, N, S, O, and $\mathrm{Fe}$ contents in P $m$ PDA-GR-Fe were 88.42, 4.94, 1.31, 3.53 , and $1.33 \mathrm{wt} \%$. The steep increase in $\mathrm{N}_{2}$ uptake at the low pressure region suggested the existence of abundant micropores. Brunauer-Emmett-Teller (BET) surface area of PmPDA-GR-Fe measured by $\mathrm{N}_{2}$ sorption/desorption isotherms is $1,105 \mathrm{~m}^{2} \mathrm{~g}^{-1}$ with an average pore size of $\sim 0.54 \mathrm{~nm}$ (Fig. 3b). Compared to the sample before acid leaching, introducing Fe species into the P $m$ PDA-GR-Fe could significantly improve the surface area and pore volume. The high specific surface area has been shown to be beneficial for promoting catalytic activity [55]. XPS revealed the presence of C (89.91 at\%), N (3.94 at\%), S (1.11 at\%), O (4.66 at\%), and Fe (0.48 at\%) (Fig. S4a). The Fe content measured from XPS is lower than that obtained from ICP-MS (1.33 wt\%), indicating that the Fe species are partially embedded within the sandwich-like structure. The high-resolution $\mathrm{N} 1 \mathrm{~s}$ spectrum (Fig. S4b) can be deconvoluted into several peaks at 398.5, 399.5, $400.3,401.3$, and $403.9 \mathrm{eV}$, which can be assigned to pyridinic $\mathrm{N}(24.3 \%), \mathrm{Fe}-\mathrm{N}$ (4.6\%), terminal graphitic $\mathrm{N}$ (10.3\%), central graphitic N (54.1\%) and oxidized $\mathrm{N}$ (6.7\%), respectively [28]. The high content of pyridinic and graphitic $\mathrm{N}$ which are also identified in the X-ray near-edge structure spectrum of N K-edge (XANES, Fig. S5a) should be beneficial for ORR [56,57]. The S $2 p$ spectrum of P $m$ PDA-GR-Fe can be fitted into three peaks (Fig. 3c). Two major peaks at 163.9 and $165.0 \mathrm{eV}$ are assigned to $S 2 p_{3 / 2}$ and $S 2 p_{1 / 2}$ peaks for the $-C-S-C-$ covalent bond of thiophene-type sulfur owning to the spin-orbit splitting [58]. The remaining peak belongs to the oxidized S. The $-\mathrm{C}-\mathrm{S}-\mathrm{C}-$ configuration was also 

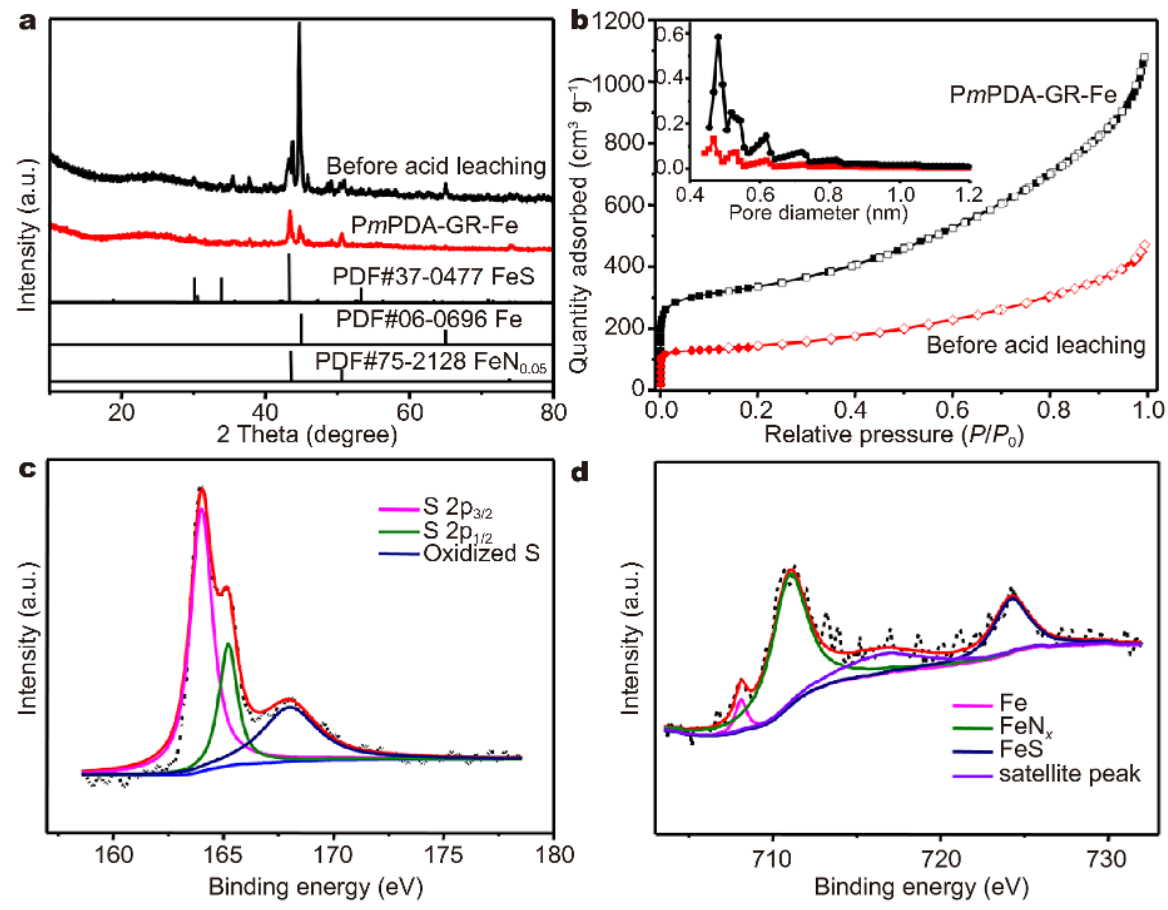

Figure 3 (a) PXRD patterns of PmPDA-GR-Fe before and after acid leaching. (b) $\mathrm{N}_{2}$ adsorption-desorption isotherms and corresponding pore size distribution (inset) of P $m$ PDA-GR-Fe before and after acid leaching. Deconvoluted XPS spectra of (c) S 2p and (d) Fe 2p peaks for the P $m$ PDA-GR-Fe catalyst.

confirmed by the XANES result (Fig. S5b) [59]. Moreover, the S L-edge XANES spectra and S $2 p$ spectra for PmPDA-GR-Fe (Fig. S6) before and after acid leaching showed that the $-\mathrm{C}-\mathrm{S}-\mathrm{C}-$ covalent bond can be stable in the acid solution. According to previous studies, $-\mathrm{C}-\mathrm{S}-\mathrm{C}-$ is beneficial for enhancing the catalytic activity of ORR [60,61]. The high-resolution Fe $2 p$ spectrum of PmPDA-GR-Fe (Fig. 3d) can be divided into three peaks for $\mathrm{FeN}_{x}(711.1 \mathrm{eV}), \mathrm{FeS}(724.03 \mathrm{eV})$, and $\mathrm{Fe}(708.1 \mathrm{eV})$ with a satellite peak at $716.8 \mathrm{eV}$ [53]. The peak at $711.1 \mathrm{eV}$ suggested the existence of Fe-N species which are active sites for ORR [28,62].

The ORR activity of P $m$ PDA-GR-Fe was first evaluated in alkaline media. CV was carried out in $\mathrm{O}_{2}{ }^{-}$and $\mathrm{Ar}-$ saturated $0.1 \mathrm{~mol} \mathrm{~L}^{-1} \mathrm{KOH}$ using commercial $\mathrm{Pt} / \mathrm{C}(20$ wt\%, Johnson Matthey). As shown in Fig. S7a, no obvious peak is observed in Ar-saturated $0.1 \mathrm{~mol} \mathrm{~L}^{-1} \mathrm{KOH}$ electrolyte, while an obvious cathodic peak can be observed in $\mathrm{O}_{2}$-saturated electrolyte, indicating that the $\mathrm{P} m \mathrm{PDA}$ GR-Fe catalyst is highly active toward ORR. The peak at $0.90 \mathrm{~V}$ from PmPDA-GR-Fe is much higher than that of $\mathrm{Pt} / \mathrm{C}(0.83 \mathrm{~V}$, Fig. S7b), suggesting excellent ORR activity of the PmPDA-GR-Fe catalyst. Meanwhile, as shown in Fig. 4a, the linear sweep voltammetric (LSV) curves confirm that PmPDA-GR-Fe exhibits prominent elec- trocatalytic activity with an onset potential $\left(E_{\text {onset }}\right)$ of $\sim 1.02 \mathrm{~V}$ and a half-wave potential $\left(E_{1 / 2}\right)$ of $\sim 0.88 \mathrm{~V}$. These values are higher than those of $\mathrm{Pt} / \mathrm{C}$ tested under the same conditions ( $E_{\text {onset }} \sim 1.0 \mathrm{~V}$ and $E_{1 / 2} \sim 0.85 \mathrm{~V}$ ). In contrast, the samples that directly pyrolyzed without iron adsorption or without using graphene as the template exhibited relatively poor performance (Fig. 4a), suggesting that both $\mathrm{Fe}$ and graphene are indispensable to achieve prominent ORR activity. Fig. $4 \mathrm{~b}$ shows the Tafel plots of both PmPDA-GR-Fe and commercial Pt/C catalysts derived from Fig. 4a. The PmPDA-GR-Fe catalyst exhibits a Tafel slope of $67 \mathrm{mV} \mathrm{dec}{ }^{-1}$ which is lower than that of the $\mathrm{Pt} / \mathrm{C}$ catalyst $\left(70 \mathrm{mV} \mathrm{dec}^{-1}\right)$, indicating PmPDA-GR-Fe has a good kinetic process for ORR. The average electron transfer number $(n)$ calculated from the RRDE measurements (Fig. 4c) at all potentials is 3.98 which is close to the value calculated from the KoutechyLevich (K-L) equation ( $n=4$, Fig. S8), confirming the desired four-electron oxygen reduction pathway. RRDE results also showed that the $\mathrm{H}_{2} \mathrm{O}_{2}$ yield remained below $3.6 \%$ at all potentials and dropped to $0.7 \%$ at $0.8 \mathrm{~V} v s$. RHE, indicating the PmPDA-GR-Fe catalyst has extremely high ORR catalytic efficiency. Moreover, the catalyst also showed high stability for ORR. The stability of PmPDA-GR-Fe and Pt/C catalysts were investigated at 

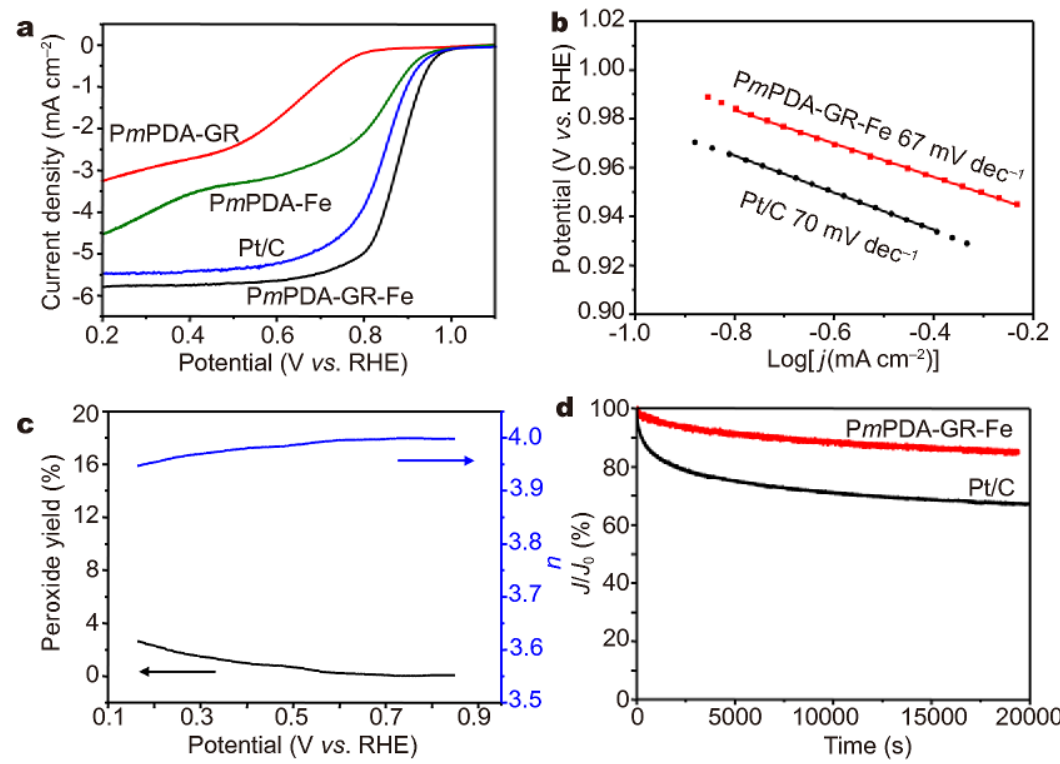

Figure 4 (a) LSV curves of PmPDA-GR, PmPDA-Fe, PmPDA-GR-Fe, and Pt/C in $\mathrm{O}_{2}$-saturated $0.1 \mathrm{~mol} \mathrm{~L}^{-1} \mathrm{KOH}$. (b) Tafel plots obtained from the $\mathrm{RDE}$ measurements on PmPDA-GR-Fe and Pt/C catalysts. (c) The peroxide yield and the calculated electron transfer number of P $m$ PDA-GR-Fe in $\mathrm{O}_{2}$-saturated $0.1 \mathrm{~mol} \mathrm{~L}^{-1} \mathrm{KOH}$ measured during ORR from RRDE tests. (d) Chronoamperometric responses of PmPDA-GR-Fe and Pt/C catalysts at $0.75 \mathrm{~V}$. Electrode rotation speed, $1,600 \mathrm{rpm}$; scan rate, $10 \mathrm{mV} \mathrm{s}^{-1}$.

$0.75 \mathrm{~V}$ in $\mathrm{O}_{2}$-saturated electrolyte for $20,000 \mathrm{~s}$ (Fig. 4d). About $86 \%$ of the original current density was retained for the PmPDA-GR-Fe catalyst, whereas $\mathrm{Pt} / \mathrm{C}$ catalyst displayed a much higher current loss of $\sim 33 \%$, clearly indicating superior stability of the P $m$ PDA-GR-Fe catalyst. Furthermore, after adding methanol to the electrolyte, no significant change was observed in the CV curve of PmPDA-GR-Fe (Fig. S9a), implying the newly synthesized catalyst was inert to the methanol crossover effect, while $\mathrm{Pt} / \mathrm{C}$ was rather vulnerable to methanol (Fig. S9b). These results demonstrate that PmPDA-GR-Fe catalyst has much better selectivity and stability than the commercial $\mathrm{Pt} / \mathrm{C}$ catalyst toward ORR in alkaline media.

To further investigate the potential application of P $m$ PDA-GR-Fe catalyst in PEMFCs, ORR activity of the P $m$ PDA-GR-Fe catalyst was examined in $0.1 \mathrm{~mol} \mathrm{~L}^{-1}$ $\mathrm{HClO}_{4}$. CV curves in Fig. S10 reveal that the PmPDAGR-Fe catalyst also possesses excellent ORR activity in acidic electrolytes. The peak potential at $0.75 \mathrm{~V} v s$. RHE of PmPDA-GR-Fe is very close to that of $\mathrm{Pt} / \mathrm{C}(0.83 \mathrm{~V})$. The LSV curves in Fig. 5a confirm that PmPDA-GR-Fe exhibits excellent ORR activity with $E_{\text {onset }}$ of $\sim 0.94 \mathrm{~V} v s$. RHE and $E_{1 / 2}$ of $\sim 0.79 \mathrm{~V} v s$. RHE. These values are comparable to those of $\mathrm{Pt} / \mathrm{C}$ tested under the same conditions $\left(E_{\text {onset }} \sim 0.96 \mathrm{~V}\right.$ and $\left.E_{1 / 2} \sim 0.83 \mathrm{~V}\right)$. In addition, the mass activity of P $m$ PDA-GR-Fe catalyst was $10.8 \mathrm{~A} \mathrm{~g}^{-1}$ at $0.80 \mathrm{~V}$, which is very competitive compared to previous studies (Table S1). Control experiments indicated that both graphene and Fe were crucial to achieve such high ORR activity in acidic electrolytes (Fig. 5a). Accordingly, Tafel plots in Fig. 5b show that the P $m$ PDA-GR-Fe catalyst has a Tafel slope of $80 \mathrm{mV} \mathrm{dec}{ }^{-1}$ which is very close to that of the $\mathrm{Pt} / \mathrm{C}$ catalyst $\left(77 \mathrm{mV} \mathrm{dec}^{-1}\right)$. The average electron transfer number $(n)$ calculated from the RRDE measurements at all potentials was 3.93, which confirmed the four-electron oxygen reduction process (Fig. 5c). RRDE results also showed that the $\mathrm{H}_{2} \mathrm{O}_{2}$ yield remained below $4.1 \%$ at all potentials and dropped to $1.9 \%$ at $0.8 \mathrm{~V}$ $v s$. RHE, indicating the PmPDA-GR-Fe catalyst has excellent ORR catalytic efficiency even in acidic media. Moreover, parallel stability tests revealed that the PmPDA-GR-Fe catalyst possessed much higher stability and better methanol tolerance than $\mathrm{Pt} / \mathrm{C}$ catalyst (Fig. $5 \mathrm{~d}$ and S11), implying that PmPDA-GR-Fe is more stable than $\mathrm{Pt} / \mathrm{C}$ toward PEMFC applications.

Obviously, the PmPDA-GR-Fe catalyst exhibits attractive ORR performance both in alkaline and acidic media, which is among the best reported ORR electrocatalysts that are active in both electrolytes (Table S2). Our control experiments confirmed that acid leaching was necessary to expose the catalytic sites by removing electrocatalytically inactive species (Fig. S12). Moreover, polyaniline (PANI) was used as the polymer precursor to form the PANI-GR-Fe catalyst, which was investigated under the same conditions. Electrocatalytic tests indicated that the catalyst prepared using PANI as the precursor 

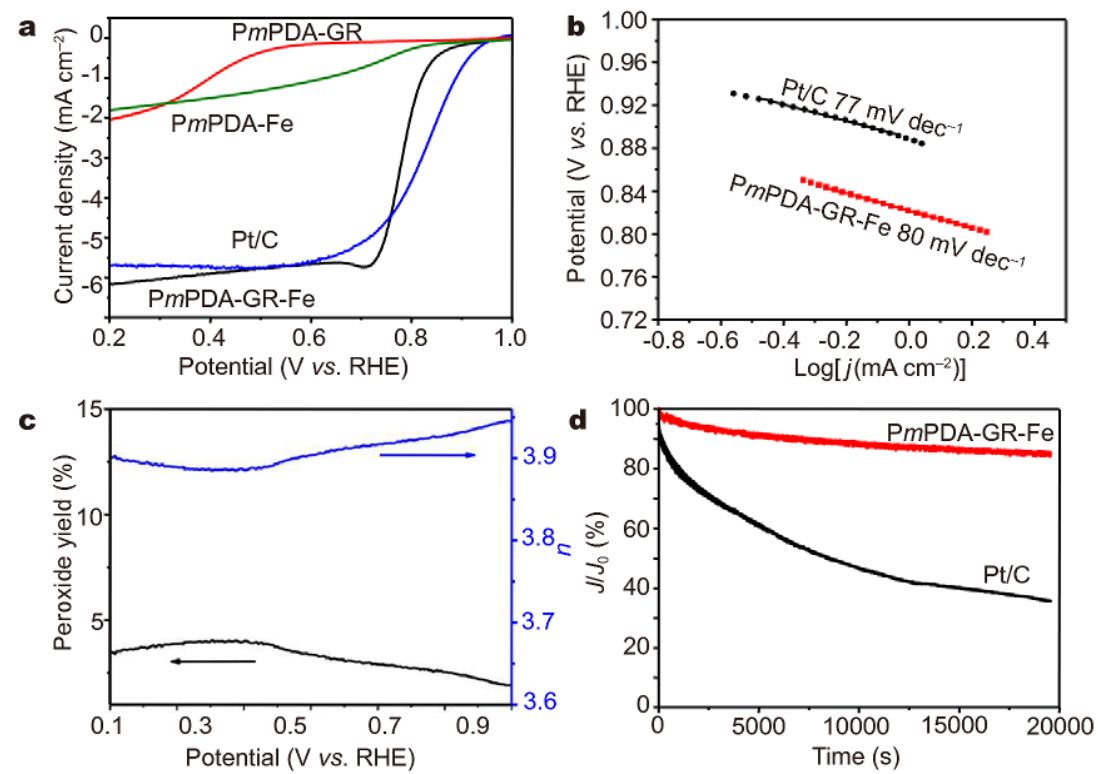

Figure 5 (a) LSV curves of PmPDA-GR, PmPDA-Fe, PmPDA-GR-Fe, and Pt/C in $\mathrm{O}_{2}$-saturated $0.1 \mathrm{~mol} \mathrm{~L}^{-1} \mathrm{HClO}_{4}$. (b) Tafel plots obtained from the $\mathrm{RDE}$ measurements on PmPDA-GR-Fe and Pt/C catalysts. (c) The peroxide yield and the calculated electron transfer number of PmPDA-GR-Fe in $\mathrm{O}_{2}$-saturated $0.1 \mathrm{~mol} \mathrm{~L}^{-1} \mathrm{HClO}_{4}$ during ORR measured from RRDE tests. (d) Chronoamperometric responses of PmPDA-GR-Fe and Pt/C catalysts at $0.7 \mathrm{~V}$. Electrode rotation speed, 1,600 rpm; scan rate, $10 \mathrm{mV} \mathrm{s}^{-1}$.

exhibited much inferior ORR performance (Fig. S13). Thus, PmPDA is indispensable to achieve the prominent ORR activity.

Subsequently, thiocyanate ion $\left(\mathrm{SCN}^{-}\right)$poisoning experiments were carried out to determine whether $\mathrm{M}-\mathrm{N}-\mathrm{C}$ is the active species in ORR. $\mathrm{SCN}^{-}$ions are known to strongly coordinate with metal ions to form stable complexes and hence poison the metal containing active sites in acidic conditions [28]. As shown in Fig. S14, the ORR activity of P $m$ PDA-GR-Fe was remarkably declined after adding $\mathrm{SCN}^{-}$into $0.1 \mathrm{~mol} \mathrm{~L}^{-1} \mathrm{HClO}_{4}$, indicating that $\mathrm{Fe}-\mathrm{N}-\mathrm{C}$ species are the primary active species for ORR. Meanwhile, to probe the possible S-doping on the catalytic activity of PmPDA-GR-Fe, the PmPDA-GO sample was washed more than 10 times to minimize the content of $S$ in the sandwich-like carbon nanosheets while ensuring that the polymerization process was not affected. EA and ICP-MS were used to quantify the variation of each element in the final catalyst. The $\mathrm{C}, \mathrm{N}, \mathrm{S}, \mathrm{O}$ and $\mathrm{Fe}$ contents in PmPDA-GR-Fe after thorough purification were $88.08,5.05,0.65,4.24$ and $1.27 \mathrm{wt} \%$, respectively. The S content obviously decreased compared to the original PmPDA-GR-Fe catalyst. The reduction of the $\mathrm{S}$ content in the catalyst caused a dramatic loss in ORR activity (Fig. S15), though the chemical nature of each element was largely unchanged (Fig. S16). Therefore, the presence of $S$ could be beneficial for enhancing ORR activity [41,47,51]. Moreover, electrochemical impedance spectroscopy (EIS) (Fig. S17) revealed that the graphenetemplated sandwich-like carbon nanosheets generally showed a much lower charge-transfer resistance than the control samples without graphene in both alkaline and acidic media, which could account for the observed prominent ORR activity of the PmPDA-GR-Fe catalyst. Furthermore, control experiments indicated that appropriate amounts of GO should be used to form the optimal sandwich-like structure (Fig. S18). Thus, the existence of multiple dopants, high surface area and unique sandwichlike structure with encapsulated conductive graphene sheets leads to the high-performance P $m$ PDA-GR-Fe catalyst.

Based on the appealing ORR activity of the PmPDAGR-Fe catalyst in electrochemical tests, we further carried out preliminary tests by using the PmPDA-GR-Fe as cathode catalyst both in a two-electrode zinc-air battery and a PEMFC. The open-circuit voltage $\left(V_{\mathrm{OC}}\right)$ of $\mathrm{P} m$ PDA-GR-Fe was $1.47 \mathrm{~V}$ with a peak power density of $280 \mathrm{~mW} \mathrm{~cm}^{-2}$, surpassing the $\mathrm{Pt} / \mathrm{C}$ cathode tested under the same conditions ( $1.45 \mathrm{~V}$ and $170 \mathrm{~mW} \mathrm{~cm}^{-2}$, Fig. 6a). The specific capacity of the battery using P $m$ PDA-GR-Fe as the cathode catalyst normalized to the mass of consumed $\mathrm{Zn}$ was $869 \mathrm{~mA} \mathrm{~h} \mathrm{~g}^{-1}$ at the discharge density of $50 \mathrm{~mA} \mathrm{~cm}^{-2}$ and $813 \mathrm{~mA} \mathrm{~h} \mathrm{~g}^{-1}$ at the discharge density of $100 \mathrm{~mA} \mathrm{~cm}^{-2}$ (Fig. S19), outperforming the battery as- 

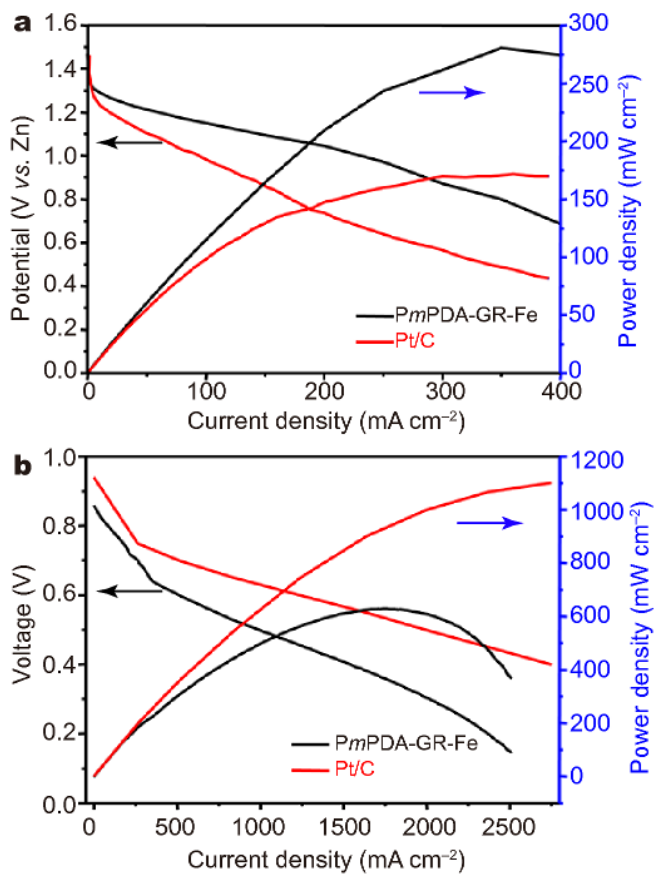

Figure 6 (a) Polarization and power density curves of the $\mathrm{Zn}$-air battery assembled using P $m$ PDA-GR-Fe and commercial Pt/C (20 wt\%) as the cathode catalysts. (b) Polarization and power density curves of the PEMFC using PmPDA-GR-Fe and commercial Pt/C (60 wt\%) as the cathode catalysts.

sembled with $\mathrm{Pt} / \mathrm{C}$ at the same mass loading. On the other hand, Fig. $6 \mathrm{~b}$ shows the fuel cell polarization curve and power density plot in the PEMFC using PmPDA-GR-Fe catalyst. The maximal power density can reach $630 \mathrm{~mW} \mathrm{~cm}^{-2}$ at cell voltage of $0.55 \mathrm{~V}$ and current density of $1,700 \mathrm{~mA} \mathrm{~cm}^{-2}$. The performance is very competitive to the $\mathrm{Pt} / \mathrm{C}$ catalyst. Note that these preliminary fuel cell results could be further improved after optimizing the MEA assembly and the fuel-cell testing conditions. These results strongly prove that the as-obtained $\mathrm{P} m \mathrm{PDA}-\mathrm{GR}$ Fe catalyst holds great potential for applications in real electrochemical devices such as zinc-air batteries and fuel cells.

\section{CONCLUSIONS}

In conclusion, we successfully demonstrated a facile method to synthesize novel sandwich-like porous carbon nanosheets using graphene as the template. In this method, GO was introduced to build the sandwich-like structure with PmPDA coated on both sides of the GO surfaces via in situ polymerization. The PmPDA could coordinate with the $\mathrm{Fe}^{3+}$ ions to generate $\mathrm{Fe}-\mathrm{N}$ active sites. Meanwhile, the introduced Fe could dramatically increase the specific surface area by forming removable nanoparticles during pyrolysis. Moreover, the S element introduced during the polymerization process is beneficial for enhancing ORR activity. Thus, this approach could create a high density of active sites by formation of various dopants on the carbon layers. More importantly, the unique planar porous structure is helpful for exposing the active sites and mass transport. Furthermore, EIS results indicate that the encapsulated graphene could significantly reduce the charge transfer resistance. These attractive features enable the P $m$ PDA-GR-Fe catalyst to exhibit excellent ORR activity in both alkaline and acidic media. We further showed that the PmPDA-GR-Fe catalyst can be successfully employed as a promising cathode catalyst both in $\mathrm{Zn}$-air batteries and PEMFCs.

\section{Received 20 November 2017; accepted 20 December 2017;} published online 8 January 2018

1 Han Y, Wang YG, Chen W, et al. Hollow N-doped carbon spheres with isolated cobalt single atomic sites: superior electrocatalysts for oxygen reduction. J Am Chem Soc, 2017, 139: 17269-17272

2 Chen Y, Ji S, Wang Y, et al. Isolated single iron atoms anchored on $\mathrm{N}$-doped porous carbon as an efficient electrocatalyst for the oxygen reduction reaction. Angew Chem Int Ed, 2017, 56: 69376941

3 Cheng F, Chen J. Metal-air batteries: from oxygen reduction electrochemistry to cathode catalysts. Chem Soc Rev, 2012, 41: 2172-2192

4 Wang ZL, Xu D, Xu JJ, et al. Oxygen electrocatalysts in metal-air batteries: from aqueous to nonaqueous electrolytes. Chem Soc Rev, 2014, 43: 7746-7786

5 Li Y, Dai H. Recent advances in zinc-air batteries. Chem Soc Rev, 2014, 43: 5257-5275

6 Jiang WJ, Gu L, Li L, et al. Understanding the high activity of $\mathrm{Fe}-$ $\mathrm{N}-\mathrm{C}$ electrocatalysts in oxygen reduction: $\mathrm{Fe} / \mathrm{Fe}_{3} \mathrm{C}$ nanoparticles boost the activity of $\mathrm{Fe}-\mathrm{N}_{x}$. J Am Chem Soc, 2016, 138: 3570-3578

7 Zhang G, Jin X, Li H, et al. N-doped crumpled graphene: bottomup synthesis and its superior oxygen reduction performance. Sci China Mater, 2016, 59: 337-347

8 He D, Xiong Y, Yang J, et al. Nanocarbon-intercalated and Fe-Ncodoped graphene as a highly active noble-metal-free bifunctional electrocatalyst for oxygen reduction and evolution. J Mater Chem A, 2017, 5: 1930-1934

9 Kuang M, Zheng G. Nanostructured bifunctional redox electrocatalysts. Small, 2016, 12: 5656-5675

$10 \mathrm{Yu} \mathrm{M}$, Zhou S, Liu Y, et al. Long life rechargeable $\mathrm{Li}_{-} \mathrm{O}_{2}$ batteries enabled by enhanced charge transfer in nanocable-like Fe@Ndoped carbon nanotube catalyst. Sci China Mater, 2017, 60: 415426

11 Zhang Y, Huang LB, Jiang WJ, et al. Sodium chloride-assisted green synthesis of a 3D Fe-N-C hybrid as a highly active electrocatalyst for the oxygen reduction reaction. J Mater Chem A, 2016, 4: 7781-7787

12 Zhang J, Sasaki K, Sutter E, et al. Stabilization of platinum oxygenreduction electrocatalysts using gold clusters. Science, 2007, 315: 220-222

13 Guan BY, Yu L, (David) Lou XW. A dual-metal-organic-framework derived electrocatalyst for oxygen reduction. Energy Environ 
Sci, 2016, 9: 3092-3096

14 Zhao D, Shui JL, Chen C, et al. Iron imidazolate framework as precursor for electrocatalysts in polymer electrolyte membrane fuel cells. Chem Sci, 2012, 3: 3200-3205

15 Yan D, Li Y, Huo J, et al. Defect chemistry of nonprecious-metal electrocatalysts for oxygen reactions. Adv Mater, 2017, 29: 1606459

16 Meng $\mathrm{F}$, Zhong $\mathrm{H}$, Bao D, et al. In situ coupling of strung $\mathrm{Co}_{4} \mathrm{~N}$ and intertwined $\mathrm{N}-\mathrm{C}$ fibers toward free-standing bifunctional cathode for robust, efficient, and flexible $\mathrm{Zn}$-air batteries. J Am Chem Soc, 2016, 138: 10226-10231

17 Zhou T, Zhou Y, Ma R, et al. Achieving excellent activity and stability for oxygen reduction electrocatalysis by hollow mesoporous iron-nitrogen-doped graphitic carbon spheres. J Mater Chem A, 2017, 5: 12243-12251

18 Xiao M, Zhu J, Feng L, et al. Meso/macroporous nitrogen-doped carbon architectures with iron carbide encapsulated in graphitic layers as an efficient and robust catalyst for the oxygen reduction reaction in both acidic and alkaline solutions. Adv Mater, 2015, 27: 2521-2527

19 Zhang C, Wang YC, An B, et al. Networking pyrolyzed zeolitic imidazolate frameworks by carbon nanotubes improves conductivity and enhances oxygen-reduction performance in polymerelectrolyte-membrane fuel cells. Adv Mater, 2017, 29: 1604556

20 Zhou T, Du Y, Yin S, et al. Nitrogen-doped cobalt phosphate@nanocarbon hybrids for efficient electrocatalytic oxygen reduction. Energy Environ Sci, 2016, 9: 2563-2570

21 Li Y, Zhou W, Wang $\mathrm{H}$, et al. An oxygen reduction electrocatalyst based on carbon nanotube-graphene complexes. Nat Nanotechnol, 2012, 7: 394-400

22 Liang $\mathrm{Y}$, Li Y, Wang $\mathrm{H}$, et al. $\mathrm{Co}_{3} \mathrm{O}_{4}$ nanocrystals on graphene as a synergistic catalyst for oxygen reduction reaction. Nat Mater, 2011, 10: 780-786

23 Yin $\mathrm{P}$, Yao T, Wu Y, et al. Single cobalt atoms with precise Ncoordination as superior oxygen reduction reaction catalysts. Angew Chem Int Ed, 2016, 55: 10800-10805

24 Liu J, Sun X, Song P, et al. High-performance oxygen reduction electrocatalysts based on cheap carbon black, nitrogen, and trace iron. Adv Mater, 2013, 25: 6879-6883

25 Ding Y, Niu Y, Yang J, et al. A metal-amino acid complex-derived bifunctional oxygen electrocatalyst for rechargeable zinc-air batteries. Small, 2016, 12: 5414-5421

26 Shang L, Yu H, Huang X, et al. Well-dispersed ZIF-derived Co,NCo-doped carbon nanoframes through mesoporous-silica-protected calcination as efficient oxygen reduction electrocatalysts. Adv Mater, 2016, 28: 1668-1674

27 Meng FL, Wang ZL, Zhong HX, et al. Reactive multifunctional template-induced preparation of Fe-N-doped mesoporous carbon microspheres towards highly efficient electrocatalysts for oxygen reduction. Adv Mater, 2016, 28: 7948-7955

28 Wang Q, Zhou ZY, Lai YJ, et al. Phenylenediamine-based $\mathrm{FeN}_{x} / \mathrm{C}$ catalyst with high activity for oxygen reduction in acid medium and its active-site probing. J Am Chem Soc, 2014, 136: 1088210885

29 Zhou R, Qiao SZ. An Fe/N co-doped graphitic carbon bulb for high-performance oxygen reduction reaction. Chem Commun, 2015, 51: 7516-7519

30 Xia W, Mahmood A, Liang Z, et al. Earth-abundant nanomaterials for oxygen reduction. Angew Chem Int Ed, 2016, 55: 2650-2676

31 Li J, Ghoshal S, Liang W, et al. Structural and mechanistic basis for the high activity of $\mathrm{Fe}-\mathrm{N}-\mathrm{C}$ catalysts toward oxygen reduction.
Energy Environ Sci, 2016, 9: 2418-2432

32 Yang J, Wang X, Li B, et al. Novel iron/cobalt-containing polypyrrole hydrogel-derived trifunctional electrocatalyst for selfpowered overall water splitting. Adv Funct Mater, 2017, 27: 1606497

33 Nie Y, Li L, Wei Z. Recent advancements in Pt and Pt-free catalysts for oxygen reduction reaction. Chem Soc Rev, 2015, 44: 2168-2201

34 Wang $\mathrm{W}$, Chen W, Miao $\mathrm{P}$, et al. $\mathrm{NaCl}$ crystallites as dual-functional and water-removable templates to synthesize a three-dimensional graphene-like macroporous Fe-N-C catalyst. ACS Catal, 2017, 7: 6144-6149

35 Gao W, Havas D, Gupta S, et al. Is reduced graphene oxide favorable for nonprecious metal oxygen-reduction catalysts? Carbon, 2016, 102: 346-356

36 Wu G, More KL, Xu P, et al. A carbon-nanotube-supported graphene-rich non-precious metal oxygen reduction catalyst with enhanced performance durability. Chem Commun, 2013, 49: 3291-3293

37 Li Q, Pan H, Higgins D, et al. Metal-organic framework-derived bamboo-like nitrogen-doped graphene tubes as an active matrix for hybrid oxygen-reduction electrocatalysts. Small, 2015, 11: 1443-1452

38 Jaouen F, Herranz J, Lefevre M, et al. Cross-laboratory experimental study of non-noble-metal electrocatalysts for the oxygen reduction reaction. ACS Appl Mater Interfaces, 2009, 1: 1623-1639

39 Zhong H, Wang J, Zhang Y, et al. ZIF-8 Derived Graphene-Based Nitrogen-Doped Porous Carbon Sheets as Highly Efficient and Durable Oxygen Reduction Electrocatalysts. Angew Chem Int Ed, 2014, 53: 14235-14239

40 Xiang Z, Xue Y, Cao D, et al. Highly efficient electrocatalysts for oxygen reduction based on $2 \mathrm{D}$ covalent organic polymers complexed with non-precious metals. Angew Chem Int Ed, 2014, 53: 2433-2437

41 Zhang $\mathrm{P}$, Sun F, Xiang Z, et al. ZIF-derived in situ nitrogen-doped porous carbons as efficient metal-free electrocatalysts for oxygen reduction reaction. Energy Environ Sci, 2014, 7: 442-450

42 Yang $\mathrm{T}$, Liu J, Zhou R, et al. N-doped mesoporous carbon spheres as the oxygen reduction reaction catalysts. J Mater Chem A, 2014 , 2: $18139-18146$

43 Liang HW, Wei W, Wu ZS, et al. Mesoporous metal-nitrogendoped carbon electrocatalysts for highly efficient oxygen reduction reaction. J Am Chem Soc, 2013, 135: 16002-16005

44 Qu K, Zheng Y, Dai S, et al. Polydopamine-graphene oxide derived mesoporous carbon nanosheets for enhanced oxygen reduction. Nanoscale, 2015, 7: 12598-12605

45 Xia BY, Yan Y, Wang X, et al. Recent progress on graphene-based hybrid electrocatalysts. Mater Horiz, 2014, 1: 379-399

46 Li S, Wu D, Cheng C, et al. Polyaniline-coupled multifunctional 2D metal oxide/hydroxide graphene nanohybrids. Angew Chem Int Ed, 2013, 52: 12105-12109

47 Qiao M, Tang C, He G, et al. Graphene/nitrogen-doped porous carbon sandwiches for the metal-free oxygen reduction reaction: conductivity versus active sites. J Mater Chem A, 2016, 4: 1265812666

48 Li S, Wu D, Liang $\mathrm{H}$, et al. Metal-nitrogen doping of mesoporous carbon/graphene nanosheets by self-templating for oxygen reduction electrocatalysts. ChemSusChem, 2014, 7: 3002-3006

49 Yan J, Yang L, Lin MF, et al. Polydopamine spheres as active templates for convenient synthesis of various nanostructures. Small, 2013, 9: 596-603 
50 Fu X, Zamani P, Choi JY, et al. In situ polymer graphenization ingrained with nanoporosity in a nitrogenous electrocatalyst boosting the performance of polymer-electrolyte-membrane fuel cells. Adv Mater, 2017, 29: 1604456

51 Wen Z, Ci S, Hou Y, et al. Facile one-pot, one-step synthesis of a carbon nanoarchitecture for an advanced multifunctonal electrocatalyst. Angew Chem Int Ed, 2014, 53: 6496-6500

$52 \mathrm{Xu} \mathrm{C}$, Zeng Y, Rui X, et al. Controlled soft-template synthesis of ultrathin C@FeS nanosheets with high-li-storage performance. ACS Nano, 2012, 6: 4713-4721

53 Zhu Y, Zhang B, Liu X, et al. Unravelling the structure of electrocatalytically active $\mathrm{Fe}-\mathrm{N}$ complexes in carbon for the oxygen reduction reaction. Angew Chem Int Ed, 2014, 53: 10673-10677

$54 \mathrm{Hu} \mathrm{Y}$, Jensen JO, Zhang W, et al. Hollow spheres of iron carbide nanoparticles encased in graphitic layers as oxygen reduction catalysts. Angew Chem Int Ed, 2014, 53: 3675-3679

55 Wang YC, Lai YJ, Song L, et al. S-doping of an Fe/N/C ORR catalyst for polymer electrolyte membrane fuel cells with high power density. Angew Chem, 2015, 127: 10045-10048

56 Zhang LS, Liang XQ, Song WG, et al. Identification of the nitrogen species on $\mathrm{N}$-doped graphene layers and $\mathrm{Pt} / \mathrm{NG}$ composite catalyst for direct methanol fuel cell. Phys Chem Chem Phys, 2010, 12: 12055-12059

$57 \mathrm{Wu}$ ZS, Chen L, Liu J, et al. High-performance electrocatalysts for oxygen reduction derived from cobalt porphyrin-based conjugated mesoporous polymers. Adv Mater, 2014, 26: 1450-1455

58 Yang Z, Yao Z, Li G, et al. Sulfur-doped graphene as an efficient metal-free cathode catalyst for oxygen reduction. ACS Nano, 2012, 6: 205-211

59 Sarret G, Connan J, Kasrai M, et al. Chemical forms of sulfur in geological and archeological asphaltenes from Middle East, France, and Spain determined by sulfur K- and L-edge X-ray absorption near-edge structure spectroscopy. GeoChim CosmoChim Acta, 1999, 63: 3767-3779

60 Wang X, Wang J, Wang D, et al. One-pot synthesis of nitrogen and sulfur co-doped graphene as efficient metal-free electrocatalysts for the oxygen reduction reaction. Chem Commun, 2014, 50: 48394842

61 Shen H, Gracia-Espino E, Ma J, et al. Synergistic effects between atomically dispersed $\mathrm{Fe}-\mathrm{N}-\mathrm{C}$ and $\mathrm{C}-\mathrm{S}-\mathrm{C}$ for the oxygen reduction reaction in acidic media. Angew Chem, 2017, 129: 13988-13992

$62 \mathrm{Wu} \mathrm{G}$, Chen Z, Artyushkova K, et al. Polyaniline-derived nonprecious catalyst for the polymer electrolyte fuel cell cathode. ECS Trans, 2008, 16: 159-170

Acknowledgements This work was supported by the National Basic Research Program of China (973 Program, 2015CB351903), the National Key Research and Development Program (2017YFA0207301), the National Natural Science Foundation of China (51402282, 21474095 and 21476104), CAS Key Research Program of Frontier Sciences (QYZDB-SSW-SLH018), and the Fundamental Research Funds for the Central Universities.

Author contributions $\mathrm{Xu} \mathrm{H}$ and Wang $\mathrm{T}$ conceived and designed the research. Wang T, Wang J, Wang X, Yang J performed the experiments. Wang T, Yang J, Wang X, Yang J, Liu J and $\mathrm{Xu} \mathrm{H}$ participated in the interpretation of experimental results. All authors participated in the general discussion.

Conflict of interest The authors declare no conflict of interest.

Supplementary information Experimental details are available in the online version of the paper. 


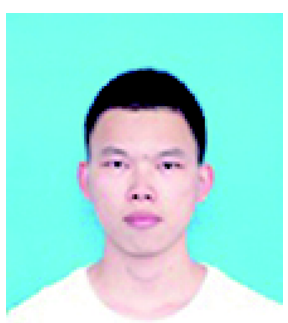

cELEATE WESTY
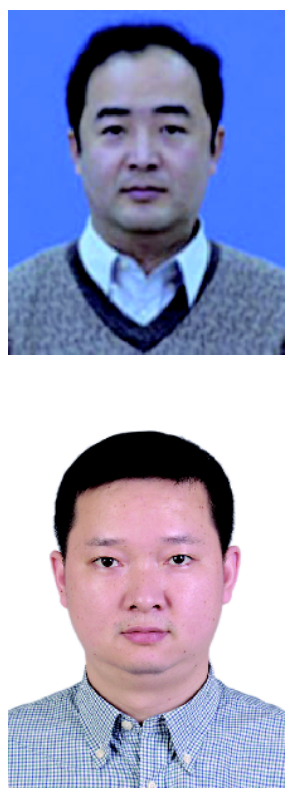

Tao Wang received his BSc degree from Hefei University of Technology in 2015. He is currently a PhD candidate in the Department of Polymer Science and Engineering, University of Science and Technology of China. His current research is developing functional polymers for flexible energy devices.
Jianguo Liu received his PhD degree from Dalian Institute of Chemical Physics in China. Then he worked as post-doc in Hong Kong University of Science and Technology and University of Newcastle upon Tyne in UK. He joined Nanjing University as an associate professor in 2007, and become a professor in 2013. His research now focuses on fuel cells and Li-ion batteries.

Hangxun Xu received his BSc degree from University of Science and Technology of China and $\mathrm{PhD}$ in Materials Chemistry from the University of Illinois at Urbana-Champaign. Thereafter, he was a Postdoctoral Research Associate with Prof. John Rogers. He came back to the USTC as a Professor in 2013 through the "National 1000 Young Talents" program. His current research focuses on developing functional polymers for applications in energy conversion and flexible electronics.

\section{石墨烯模板法制备类似三明治结构的多孔碳纳米片用于高效催化酸/碱性条件下氧还原反应的研究}

汪韬 ${ }^{1}$, 王健宇 ${ }^{2}$, 王绪 ${ }^{1}$, 杨佳 ${ }^{1}$, 刘建国 ${ }^{2^{*}}$, 徐航勋 ${ }^{1^{*}}$

摘要 开发低成本, 高性能氧还原反应(ORR)电催化剂对于燃料电池和金属空气电池的规模化应用至关重要. 基于石墨烯的碳催化剂已经 被广泛用于碱性电解质中的ORR. 然而, 与 $\mathrm{Pt} / \mathrm{C}$ 催化剂相比, 石墨烯基催化剂在酸性电解质中的性能仍然需要进一步提升. 在这个工作中, 我们发展了一种非常高效的模板方法来制备基于石墨烯的具有三明治结构的多孔碳纳米片电催化剂, 其在碱性和酸性电解质中均具有非 常好的ORR催化性能. 首先, 被氧化石墨烯吸附的苯二胺分子通过氧化聚合形成富氮聚合物网络, 接着铁 $(\mathrm{Fe})$ 盐被吸附到聚合物网络中, 并 且在热解之后形成ORR活性位点 $\mathrm{Fe}-\mathrm{N}-\mathrm{C}$ 以及 $\mathrm{Fe}, \mathrm{FeS}$ 和 $\mathrm{FeN}_{0.05}$ 纳米颗粒, 最终得到类似三明治结构的碳纳米片 ORR电催化剂. 由于这种结 构中存在较高密度的ORR活性位点, 所获得的催化剂显示出非常高效的ORR活性, 在 $0.1 \mathrm{~mol} \mathrm{~L}^{-1} \mathrm{KOH}$ 中半波电位比 $\mathrm{Pt} / \mathrm{C}$ 高 $30 \mathrm{mV}$. 更重要 的是, 在 $0.1 \mathrm{~mol} \mathrm{~L}^{-1} \mathrm{HClO}_{4}$ 中, 催化剂的半波电位仅比 $\mathrm{Pt} / \mathrm{C}$ 低约 $40 \mathrm{mV}$. 这种独特的平面三明治结构可以在催化反应中暴露出丰富的 $\mathrm{ORR}$ 活 性位点, 同时, 石墨烯层和多孔结构可以提高电导率以及促进传质, 这两者对于实现高活性ORR催化至关重要. 在碱性和酸性条件中, 突出 的电催化活性和耐久性表明这些碳纳米片作为贵金属基ORR催化剂的替代物具有很大的潜力, 优秀的锌空气电池和质子交换膜燃料电池 性能直接证实这种材料在实际电化学能源转化装置中也非常有应用前景. 